\title{
ARTICLE
}

\section{The Antecedents of Women's Crack Cocaine Abuse: Family Substance Abuse, Sexual Abuse, Depression and Illicit Drug Use}

\author{
CAROL J. BOYD, PhD, RN \\ School of Nursing, University of Michigan, Ann Arbor
}

\begin{abstract}
Young African-American women are the fastest growing group of crack cocaine users in the United States. Despite this increase, relatively little is known about women who use crack cocaine and the possible reasons for their drug use. This descriptive, exploratory study focused on data from a sample of 105, predominantly African-American women who use(d) crack cocaine, of whom 60 were in drug treatment and 45 were still using crack cocaine. Significant correlations were found between variables such as family drug use, first age of sexual abuse, age of first depressive symptoms and age of first illicit drug use. These data are consistent with other studies which have noted high rates of depression and sexual abuse in samples of predominantly Euro-American, alcoholic women. Implications for the treatment of women are discussed.
\end{abstract}

Keywords - women; substance abuse; crack cocaine; sexual abuse; depression.

BETWEEN 1988 AND 1991, frequent crack cocaine use increased among young, urban women (Krajewski, 1988; U.S. General Accounting Office, 1991). Despite this increase, addiction researchers have shown a noteworthy lack of interest in examining either the etiology or the treatment factors related to women's crack cocaine use. When we have studied issues related to women's street drug use, it is often out of regard for her baby, not necessarily for the woman. In the future, researchers must embrace what should be a very important health concern, the increasing numbers of women who are using illicit drugs - particularly crack cocaine - and the reasons for this increase.

This research was supported by the National Institute on Drug Abuse, Grant No. 1-K20 DA 00150-02.

An earlier version of this paper was presented at the Midwest Nursing Research Society's Annual Conference, Chicago, March, 1992.

Special thanks to Dorothy Henderson, MS, RN and Stephanie McVey for their assistance with this investigation. I am grateful to Odyssey House, Flint, MI and Evangeline Women's Program, Detroit, MI for their support.

Request for reprints should be addressed to Carol J. Boyd, PhD, RN, Assistant Professor, School of Nursing, University of Michigall, 400 N. Ingalls, Division 1, Ann Arbor, MI 48109.
It is evident that multiple factors contribute to a woman's addiction to alcohol and other drugs; a complex interplay among environmental, psychological and biological conditions appear to influence the initiation and maintenance of her substance use. Unfortunately, because so few studies of illicit drug users have focused on female populations, these factors and their relationships to women's crack cocaine addictions are not well understood.

Toward the goals of increasing our understanding of women who use crack cocaine as well as developing more effective drug treatment interventions, this descriptive, correlational study was undertaken for the purposes of: describing family substance abuse, sexual abuse, depression and drug use histories in a sample of predominantly African-American women who either currently use crack cocaine or who are in treatment for their use of it; examining the interrelationships between family substance abuse, sexual trauma, depression and illicit drug use; and finally, to highlight the treatment implications inferred from these data.

In the following literature review, women who abuse alcohol or illicit drugs are discussed as if they are part of the same population of crack cocaine- 
addicted women. Unfortunately, studies of women who abuse cocaine are so limited that recent data have not been reported. Therefore, we must infer to cocaine using women from research on women with other addictions.

\section{BACKGROUND}

\section{Sexual Abuse and Parental Substance Abuse}

Most experts agree that experiences of childhood sexual abuse are underreported. Despite these underreportings, there are indications that the incidence of childhood sexual abuse and sexual trauma in populations of alcoholic or drug-addicted women are very high (Teets, 1990; Young, 1990). Indeed, it has been suggested that sexual abuse may be an etiologic factor in women's substance abuse (Benward \& DensenGerber, 1971; Davis, 1990), and adult women who have been sexually abused often demonstrate low selfesteem, depression and self-destructive behaviors (Hurley, 1991; Justice \& Justice, 1979).

When sampling addicted women, estimates of childhood sexual abuse and sexual trauma vary dramatically, with 32\% (Harrison, 1989), 44\% (Benward \& Densen-Gerber, 1971), 45\% (Bollerud, 1990), 67\% (Boyd, 1992, March), and 75\% (Yandow, 1989) being reported by various authors. Some of these differences are due to variant definitions of sexual abuse and the substance abusing populations being described. However, these differences also stem from another methodological issue; for instance, who asks-and when they ask (the sexual abuse questions) - may determine what will be reported. Future research will need to address both the researcher's definition of sexual abuse as well as data collection and interviewer's skill.

Yandow (1989) estimated that approximately $75 \%$ of alcoholic women who enter treatment have a history of sexual abuse and Boyd (1992, March) reported that $67 \%$ of the female drug users enrolled in an urban treatment program reported childhood sexual abuse. Supporting Yandow's and Boyd's data, Miller, Downs, Gondoli, and Keil (1987) reported on data from 45 alcoholic women and a comparison group of 40 randomly selected women. They found that alcoholic women were more likely to have been sexually abused and to have had a greater number of types of sexual abuse experiences. Even when controlling for demographic variables, the presence of childhood sexual abuse was a variable that discriminated between alcoholic women and the comparison group (Miller et al., 1987).

Alcohol and cocaine abusing women frequently report family histories of substance abuse (Boyd \& Mieczkowski, 1990; Iarrison, 1989; Hurley, 1991; Toray, Coughlin, Vuchinich, \& Patricelli, 1991) and it is likely that family drug/alcohol abuse is at least one an- tecedent to a woman's initiation to substance use and to the occurrence of sexual abuse. Parental substance abuse sets the stage for a form of parenting that is characterized by inattentiveness and lack of parental protection (Miller et al., 1987). This parenting style, which leads to the psychological isolation of the child, has the effect of making the girl more vulnerable to being victimized by males in her environment as well as unlikely to confide if an abusive experience occurs (Miller et al., 1987). Also, parental drug use creates an environment where drugs are readily available and where alcohol and drug consuming behaviors are modeled within the family environment. Although there are few studies reporting family drug use among populations of crack cocaine using women, Davis's (1990) observations of drug users may be relevant to cocaine abusing women. She notes that ". . . poor parental role modeling, parental substance abuse and high rates of physical and sexual abuse have been identified as characteristics of the family histories of [female] drug addicts" (Davis, 1990, p. 226).

\section{Depression}

Epidemiologists have noted that $53 \%$ of adults who have a drug problem also have a coexisting mental disorder (Sobel, 1991). However, these co-morbidity statistics fail to capture gender differences among drug abusers. For instance, when compared to male substance abusers, women substance abusers display significantly more affective disorders (Beck, Steer, \& Shaw, 1984; Blume, 1989, May; Griffin, Weiss, Mirin, \& Lange, 1989; Ojehagen, Berglund, Appel, Milsson, \& Skjaerris, 1991), lower self-esteem and greater anxiety and depression (Colton, 1981; Nurco, Wenger, \& Stephenson, 1982; Reed \& Moise, 1979).

Griffin et al. (1989), using a convenience sample of 95 men and 34 women, found that women were more likely to present for cocaine abuse treatment with a dual diagnosis of major depression, while men were more likely to be diagnosed with antisocial personality disorder. Additionally, Griffin reported that women in treatment for their cocaine addiction experienced a slower treatment recovery from the depressive symptoms than did men.

Christie's (Christie et al., 1988) data support these co-morbidity rates as well as a temporal ordering of the morbidities. In their survey of nearly 5,000 people between the ages of 18 and 30, they reported that $22.3 \%$ had a substance abuse disorder with $80 \%$ of these substance abusers also having depressive and anxiety disorders. For all substance abusers, depression or anxiety preceded the addiction $75 \%$ of the time. The young adult who had had a major depressive or anxiety disorder was twice as likely to develop a drug abuse problem when compared to those without a psychiatric history. These data support Gomberg and 
Lisansky's (1984) assertion that depression is one of the most frequently discussed antecedents of female alcohol abuse.

\section{HYPOTHESES}

1. There will be positive correlations between the following variables: age of first sexual abuse, age of first depressive episode and age of first illicit drug use (Figure 1).

2. There will be negative correlations between the number of family members who abuse alcohol or other drugs and the age of first sexual abuse, age of the first depressive episode and age of first illicit drug use (Figure 1).

\section{METHODS}

\section{Sample}

A convenience sample of 105 , primarily urban, African-American women $(\mathbf{9 4 \%})$ was used in this study. At the time, 60 of the women were receiving inpatient drug treatment and 45 were still on the street. The two groups of women did not significantly differ on any of the study variables with the one exception of the age of first sexual abuse. Those women not in treatment reported an older age. This difference may be due to women in treatment being more likely, when compared to women not in treatment, to discuss their negative sexual experiences.

The mean age of the sample was 31 years. Fifty-six percent (59) of the women had never been married and $83 \%$ (87) of the women had an average of 3 children. Fifty-five percent (57) had at least a high school diploma. Most women had used other drugs before cocaine, with $74 \%$ (78) of the women reporting they first used marijuana and $50 \%$ reported using it within the last 2 years. On the average, these participants began their illegal drug use at 16 years of age. Only 7 women began using crack cocaine as their first illegal drug; most participants were initiated to crack by their 26th

\begin{tabular}{|c|c|c|c|c|}
\hline & $\# 1$ & $\# 2$ & $\# 3$ & $\$ 4$ \\
\hline $\begin{array}{l}\text { \#1 } \\
\text { Age of 1st } \\
\text { Drug Use }\end{array}$ & 1.00 & & & \\
\hline $\begin{array}{l}\text { \#2 } \\
\text { Age of 1st } \\
\text { Sex Abuse }\end{array}$ & + & 1.00 & & \\
\hline $\begin{array}{l}\stackrel{\# 3}{\text { Age of First }} \\
\text { Depression }\end{array}$ & + & + & 1.00 & \\
\hline $\begin{array}{l}\text { \#4 } \\
\text { No. of Family } \\
\text { Members Using } \\
\text { Drugs }\end{array}$ & - & - & - & 1.00 \\
\hline Accept & eve 1 & signif & We is & at $p \leq .05$ \\
\hline
\end{tabular}

FIGURE 1. Hypothesized relationship. birthdays. The mean amount spent on crack was $\$ 672.00$ / week. Twenty-four percent (25) reported that they were also addicted to alcohol.

\section{Procedure}

This descriptive study was part of an ongoing, 5-year investigation on the factors related to female cocaine abuse. In order to be eligible for this investigation, women needed to be over the age of 18 years, to have used cocaine prior to treatment or be using a minimum of $\$ 100.00 /$ week. Because women were reporting on criminal activities, a Certificate of Confidentiality (Department of Health and Human Services) was obtained by the investigator and all participants were alerted to this binding protection. Each woman was interviewed for approximately 2-4 hours using the Boyd Substance Abuse Survey for Women. In most cases a research assistant asked the questions and recorded the woman's answers. However, if the participant wanted to read and answer the more sensitive questions herself, she was allowed to do this. In these cases, a research assistant sat with the participant and guided her through the process. At the end of the interview, the woman received $\$ 20.00$ compensation.

\section{Instruments}

The Boyd Substance Abuse Survey for Women (B-SAS) was developed for this project and is a structured interview schedule consisting of demographic questions, a drug and alcohol history, open-ended questions and several standardized scales. This interview was designed for women, to administer to other women. The B-SAS provides data on environmental, social, family, health and psychological factors related to women's initiation to and maintenance of their drug use.

For the purposes of this study, sevcral items were used to examine the variables of family drug use, age of first sexual abuse, age of first depression and past and current drug use.

Family Drug/Alcohol Abuse. Using a family genogram, women were asked about 3 generations of family drug/alcohol abuse. Women reported on alcohol abuse, drug abuse or both alcohol and drug abuse for each family member. These data were handled as categorical, with women either having a mother who is (was) alcoholic or drug addicted, a father who is (was) alcoholic or drug addicted and siblings who are (were) alcoholic or drug addicted. The number of family members who are or were substance abusers was summed and the total score was used as the measure of family substance abuse.

Sexual Abuse. Women were asked if they had ever had an experience of sexual abuse, that is, when an older, 
bigger or stronger person did sexual things to them that they did not want or like. If they answered yes, they were asked to provide more detail of the experience(s) such as their ages when it began and ended, number of times it occurred, who the perpetrator was and their descriptions of the experience. The age of the first sexual abuse experience was used in the statistical analyses for this study.

Depression. Whether a history of depressive syptomatology was present and the age it began was determined by using portions of the Diagnostic Interview Schedule (DIS). The DIS has been used in multiple alcohol and drug studies and was developed by the authors of the DSM-III. If administered correctly, this interview schedule allows for clinical diagnostics and it was useful in detcrmining the age that a person first began experiencing depressive symptoms. It was this age that was used in these analyses.

\section{RESULTS}

Sixty-one percent (65) of the women reported at least one sexual abuse experience with 42 women $(44 \%)$ reporting that it happened more than once. Sixty percent (40) of those who were abused stated that the perpetrator was a male family member; over $67 \%$ had their first experience before the age of 17 (Table 1). The mean age when the abuse stopped was 19 years.

Seventy percent (74) of the women stated they had 3 or more depressive symptoms for more than 2 weeks in their life; 17 women made at least one suicide attempt. Thirty-one percent (15) reported depressive symptoms by the age of 15 years. The modal age of first symptoms was 14 years; however, due to the extreme range, the mean was 21.6 years (See Table 1).

Most women began their illicit drug use around the age of 16 years, with $74 \%$ beginning with marijuana and only 7 stating their illegal drug use began with crack cocaine. Eighty-seven percent of the women had used an illicit drug by the age of 20 years. On an average, women smoked marijuana 1 year before they con-

TABLE 1

Ages of First Sexual Abuse, Depressive Episode and Substance Use

\begin{tabular}{lrrrr}
\hline & Mode & Mean & Range & SD \\
\hline $\begin{array}{c}\text { Age of } 1 \text { st sexual abuse } \\
(n=65)\end{array}$ & 9 & 13.9 & $1-29$ & 6.2 \\
$\begin{array}{c}\text { Age of } 1 \text { st depressive } \\
\text { symptoms }(n=49)\end{array}$ & 16 & 21.6 & $8-42$ & 8.1 \\
$\begin{array}{c}\text { Age of } 1 \text { st illicit drug use } \\
(n=105)\end{array}$ & 16 & 16 & $1-35$ & 5.1 \\
$\begin{array}{c}\text { Age of } 1 \text { st alcohol use } \\
(n=76)\end{array}$ & 15 & 17 & $7-48$ & 5.8 \\
\hline
\end{tabular}

sumed alcohol. The mean age of first alcohol use was 17 years.

It was hypothesized that there would be significant, positive correlations between age of first sexual abuse experience, age of first depressive symptoms and age of first illicit drug use. There was a strong correlation $(.52, p<.001)$ between age of first drug use and age of first depressive episode but only a moderate relationship between age of first drug use and age of first sexual abuse (See Table 2). Relative to the variable of sexual abuse, there was a moderate and significant relationship $(.48, p<.000)$ between the age the abuse began and the age the of sexual abuse stopped. Predictably, women who reported earlier abuse also reported a greater number of abuse experiences.

Ninety-seven women knew about their mothers and of these mothers, approximately $33 \%$ (32) abused alcohol or other drugs. Ninety-three women knew about their fathers and of these fathers, approximately $61 \%$ (57) were alcohol or drug abusers. Seventy-nine of the women reported having at least one sister and of these sisters, $39 \%$ were substance abusers. Fifty-six women had a second sister, $19 \%$ of whom were substance abusers. Fifty women had at least one brother and $50 \%$ of these brothers were substance abusers. Of the 54 women who had a spouse or partner, 59\% (32) stated that their partners were alcohol or drug abusers.

A family substance abuse variable was created by summing all of the substance abusing family members. This variable was used to determine bivariate correlations between the number of family members who abused substances, age of first sexual abuse experience, age of first depressive episode, age of first illicit drug use and number of sexual abuse experiences. Family drug abuse weakly correlated $(-.16, p<.06)$ with age of first drug use and age of first sexual abuse ( -.20 , $p<.066$ ) and these relationships were not statistically significant at the .05 level (Table 2). The correlation between the number of family members who abused drugs or alcohol and the age of first drug use was in the predicted direction; women with more drug using family members reporting earlier illicit drug use.

\section{DISCUSSION}

The purpose of this investigation was to describe the relationships between the variables: number of family members who abuse drugs or alcohol, age of first sexual abuse experience, age of first depressive symptoms, and age of first illicit drug use. It was hypothesized that there would be significant relationships between the variables of age of the first sexual abuse experience, first depression, first drug use and family member drug abuse and for the most part, these hypothesized relationships were supported by the data. However, several of the relationships were weak or didn't meet the significance level of .05. This lack of 
TABLE 2

Zero-order Correlations between Ages of Sexual Abuse, Depression, First Drug Use and Family Drug Use

\begin{tabular}{|c|c|c|c|c|}
\hline & $\# 1$ & $\# 2$ & $\# 3$ & $\# 4$ \\
\hline \#1 Age of 1st drug use & 1.00 & & & \\
\hline$\# 2$ Age of 1 st sex abuse & $.25^{\star}(63)$ & 1.00 & & \\
\hline$\# 3$ Age of 1 st depression & $.52^{* *}(49)$ & $.30^{\star \star}(34)$ & 1.00 & \\
\hline \#4 No. of family members using drugs & $-.16^{*}(98)$ & $-.20(58)$ & $-.05(44)$ & 1.00 \\
\hline
\end{tabular}

${ }^{*} p<.05 * * p<.001$

support may be due to the small, homogeneous sample as well as to the operationalization of the family substance abuse and sexual abuse variables. For instance, because the family substance abuse variable is derived from the summing of siblings and parents who are substance abusers, if a woman has no sisters and brothers, she cannot have as high a score as someone might with sisters and brothers. Indeed, this is a major limitation of this measure and in the future, a better way of assessing family substance abuse needs to be considered. However, by using the sum of family members with a substance abuse problem to create this variable, the variable does yield a gross estimate of the participant's exposure to family members who use drugs.

It is possible that sexual abuse was defined too broadly, particularly given this investigator's interest in the ages at which events began. If the operational definition had been limited to childhood sexual abuse experiences, perhaps the factors of family drug abuse and the participant's age of first drug use would have been clearer. Future studies using larger, more representative samples will be needed to consider these issues.

The results from this study indicate that a significant number of women who use crack cocaine have a history of sexual abuse and depressive symptoms. Although the interactive effects among these variables were not studied, the high rates of sexual abuse and depression found in this study concur with research using samples of alcoholic or heroin-addicted women. Since 3 out of $4(78 \%)$ participants scored positive for earlier depressive symptoms, these data also support those researchers (e.g., Christie et al., 1988; Griffin et al., 1989) who report high co-morbidity rates in populations of addicted people.

It appears that women may come to their substance use via a set of events that link family drug use, sexual trauma and depression to their drug use and these data indicate that sexual abuse may have preceded illicit drug abuse and depression. Since the result of both parental drug abuse (often with negligence) and sexual trauma is an assault to the self - with attendant low self-esteem, depression and anxiety - a woman's drug usc may function as an attempt to mediate against the sequela of feelings which follow hurtful childhood experiences. Clearly, the temporality and interactive effects of these variables need further investigation.

One implication of these research findings pertain to the treatment of drug addicted women, particularly women who use crack cocaine. Women who come into treatment must be assessed for co-existing psychopathology, particularly depression. With the likelihood of depression and addiction co-existing in crack cocaine using women, centers that treat women for substance abuse must be prepared to employ a dual diagnostic model, concomitantly providing support and treatment for the addiction and the depression.

Women entering drug treatment need to be asked about prior sexual abuse experiences and assessed for the symptoms that often follow such experiences. If research continues to demonstrate that approximately 2 out of 3 female substance abusers have had a prior sexual abuse experience, usually before the age of 16 years, treatment programs that incorporate techniques for treating incest survivors may be needed. Additionally, the sex of the therapist and the composition of therapy groups should be reconsidered when treating women recovering from sexual abuse as well as addiction.

With so many of the women reporting family members who abuse alcohol or other drugs, treatment personnel may need to assess the families of their female patients and whenever possible, offer family therapy. At the very least, women in treatment should be given a chance to discuss the substance abusing environment in which they were reared and to which they may return. Strategies for coping with significant others who abuse alcohol/drugs need to be incorporated into the treatment plan.

\section{CONCLUSION}

In the past, addiction researchers have paid too little attention to women's addictions in general and more specifically, to the study and treatment of women who use street drugs. This past neglect is becoming evident when we start examining issues related to the treatment of women's substance abuse. Data from this study indicate that we must consider the likelihood that sex- 
ual abuse and depression may be significant variables in the treatment of women who abuse crack cocaine.

\section{REFERENCES}

Beck, A., Steer, R., \& Shaw, B. (1984). Hopelessness in alcoholand heroin-dependent women. Journal of Clinical Psychology, 40(2), 602-606.

Benward, J., \& Densen-Gerber, J. (1971). Incest as a causal factor in antisocial bchavior: An cxploratory study. Contemporary Drug Problems: A Law Quarterly, 1, 323-340.

Blume, S. (1989, May). Chemical dependency in women. Paper presented at the American Academy of Psychiatrists in Alcoholism and Addictions. San Francisco.

Bollerud, K. (1990). $\Lambda$ model for the treatment of trauma-related syndromes among chemically dependent inpatient women. Journal of Substance Abuse Treatment, 7, 83-87.

Boyd, C., \& Mieczkowski, T. (1990). Drug use, health, family and social support in crack cocaine users. Addictive Behaviors, 15, $481-485$.

Boyd, C. (1992, March). Cocaine and women: The scope of the problem. Paper presented at the Crack Exposed Infants and Children Conference sponsored by Children's Hospital, Detroit, MI.

Christie, K., Burke, J., Regier, D., Rae, D., Boyd, J., \& Locke, B. (1988). Epidemiologic evidence for early onset of mental disorders and higher risk of drug abuse in young adults. American Journal of Psychiatry, 145(8), 971-975.

Colton, M. (1981). A descriptive and comparative analysis of self perceptions and attitudes of heroin addicted women. In A.J. Schecter (Ed.), Drug dependence and alcoholism, vol. I. New York: Plenum Press.

Cuskey, W.R., Berger, L.H., \& Densen-Gerber, J. (1981). Issues in the treatment of female addiction: A review and critique of the literature. In E. Howell \& M. Bayes (Eds.), Women and mental health (pp. 269-295). New York: Basic Books

Davis, S. (1990). Chemical dependency in women: A description of its effects and outcome on adequate parenting. Journal of Substance Abuse Treatment, 7, 225-232.

Gawin, F., \& Ellinwood, E. (1988). Cocaine and other stimulants. New England .Iournal of Medicine, 318(18), 1173-1182.

Gomberg, E.S.L., \& Lisansky, J.M. (1984). Antecedents of alcohol problems in women. In S.C. Wilsnack, \& L.J. Beckman (Eds.), Alcohol problems in women: Antecedents, consequences and intervention (pp. 233-259). New York: Guilford Press.
Griffin, M., Weiss, R., Mirin, S., \& Lange, U. (1989). A comparison of male and female cocaine abusers. Archives of General Psychiatry, 46, 122-126.

Harrison, P. (1989). Women in treatment: Changing over time. The International Journal of the Addictions, 24(7), 655-673.

Hurley, D.L. (1991). Women, alcohol and incest: An analytical review. Journal of Studies on Alcohol, 52(3), 253-267.

Justice, B., \& Justice, R. (1979). The broken taboo. New York: Human Sciences Press.

Krajewski, K.J. (1988). Crack and cocaine- Current medical issues. Texan Medicine, 1984, 9, 48-50.

Miller, B., Downs, W., Gondoli, D., Keil, A. (1987). The role of childhood sexual abuse in the development of alcoholism in women. Violence and Victims, 2(3), 157-172.

Nurco, D., Wenger, N., \& Stephenson, P. (1982). Female narcotic addicts. Changing profiles. Focus on Women: Journal of Addictions and Health, 3(2), 62-96.

Ojehagen, A., Berglund, M., Appel, C., Milsson, B., \& Skjaerris, A. (1991). Psychiatric symptoms in alcoholics attending outpatient treatment. Alcoholism: Clinical and Experimental Research, 15(4), 640-646.

Reed, B., \& Moise, R. (1979). Implications of treatment and future research. Addicted women: Family dynamics, self-perceptions, and supported systems. (U.S. Department of Health, Education and Welfare Publication No. (ADA) 80-762). Washington, DC: U.S. Government Printing Office.

Sobel, K. (1991). Study shows striking overlap of substance abuse, mental illness. NIDA Notes, 6(2), 20.

Teets, J. (1990). What women talk about: Sexuality issues among chemically dependent women. Journal of Psychosocial Nursing, 28(12), 4-7.

Toray, T., Coughlin, C., Vuchinich, S., \& Patricelli, P. (1991). Gender differences associated with adolescent substance abuse: Comparisons and implications for treatment. Family Relations, 4, $338-344$.

U.S. General Accounting Office. (1991). The crack cocaine epidemic: Health consequences and treatment. Fact Sheet for the Chairman, Select Committee on Narcotics Abuse and Control, House of Representatives (No. GAO/HRD-91-55FS).

Yandow, V. (1989). Alcoholism in women. Psychiatric Annals, 19, 243-247.

Young, E. (1990). The role of incest issues in relapse. Journal of Psychoactive Drugs, 22(2), 249-258. 